\section{Shock Timing and Yield Sensitivity Studies for NIF Ignition Capsules}

\author{
R. E. Olson \\ Sandia National Laboratories \\ Albuquerque, NM 87185
}

\section{RECEIVED \\ NOV 291999 \\ OS T:}

\begin{abstract}
A cryogenic, $\beta$-layered NIF ignition capsule with a beryllium ablator that employs a $\mathrm{BeO}$ dopant $(2 \% \mathrm{O})$ for opacity control is described. The design has an optimized yield of $12 \mathrm{MJ}$ and uses a "reduced drive" hohlraum temperature pulse shape that peaks at $\sim 250 \mathrm{eV}$. Shock timing sensitivity calculations have been performed for this capsule design. Individual uncertainties of: 1) $\sim 200 \mathrm{ps}$ in the timing of the foot pulse; 2) $\sim 5 \%$ in the $x$-ray flux of the foot pulse and first step; 3) $\sim 10 \%$ in the ablator EOS; or 4) $\sim 5 \mu \mathrm{m}$ in the DT ice layer thickness each have a significant impact on thermonuclear yield. Combined uncertainties have greater impact than isolated, individual issues. For example, a combination of uncertainties of: $200 \mathrm{ps}$ in the foot $+2 \mathrm{eV}$ in the foot $+5 \mu \mathrm{m}$ in the DT thickness results in a calculation that produces only $\sim 1 \%$ of the original design yield. A second, more speculative, capsule concept utilizing a liquid DT ablator is also discussed. This design produces a $5 \mathrm{MJ}$ yield in a $250 \mathrm{eV}$ peak drive calculation.
\end{abstract}

\section{INTRODUCTION}

Numerical simulations indicate that the success of indirect-drive ignition capsules in the National Ignition Facility (NIF) will depend critically upon our ability to reduce the uncertainties in target $x$-ray drive and shock timing measurements. For this reason, capsule optimization and sensitivity calculations are an important component in the NIF ignition campaign ${ }^{1,2}$ and have milestones that are tied directly to diagnostic development for ablator burnthrough and shock propagation experiments. Such calculations will set the performance requirements for several of the key NIF ignition diagnostics $^{3}$. In particular, specifications for the ASBO (active shock breakout), VISAR (velocity interferometry system for any reflecting surface), SXI (streaked x-ray imager), Dante (a $\mathrm{K}$ - and L- edge filtered photocathode array), and streaked radiography NIF diagnostics will depend upon the calculations of ignition capsule shock timing sensitivities.

To date, there exist about a half-dozen indirect-drive NIF ignition target designs based upon fully-integrated 2D radiation-hydrodynamics calculations (i.e, calculations including laser beam input, hohlraum behavior, and capsule implosion). Recent overviews of these calculations can be found in References 4 and 5. For the purpose of setting NIF ignition diagnostic requirements, it is of interest to examine sensitivities for capsules based upon the most marginal of the drive parameters that might be seriously considered for ignition on NIF. Such a "reduced scale" ( $900 \mathrm{~kJ}, 250 \mathrm{TW}$ laser) NIF ignition target has been developed by Dittrich, et al. ${ }^{6}$ In that design, a radially varying copper dopant is used for controlling the opacity in a beryllium ablator. More recently, thought has been given as to how the level of $\mathrm{Cu}$ dopant might be reduced or eliminated so as to absorb more energy from a reduced drive NIF hohlraum ${ }^{7}$. A possible solution might be found in capsule designs proposed over the past several years at Sandia National Laboratories. Sandia indirectdrive $\mathrm{Be}$ ablator capsules employing $\mathrm{BeO}$ as the only opacity control dopant have been used in calculations of a light ion beam target $^{8}$ and $\mathrm{z}$-pinch targets ${ }^{9}$.

In the present work, the spectrally-dependent capsule $\mathrm{x}$-ray drive for the $900 \mathrm{~kJ} \mathrm{NIF}$ hohlraum ${ }^{6}$ is used as input in sensitivity studies for the $\mathrm{Be}+\mathrm{BeO}$ ignition capsule shown in Figure 1. This capsule is based upon a modified version of the Sandia z-pinch ignition capsule ${ }^{9}$. As will be shown in Section II, the NIF version of this $\mathrm{Be}+\mathrm{BeO}$ ignition capsule has been optimized to produce a yield of $12 \mathrm{MJ}$ in $1 \mathrm{D}$ calculations, but is sensitive to shock timing

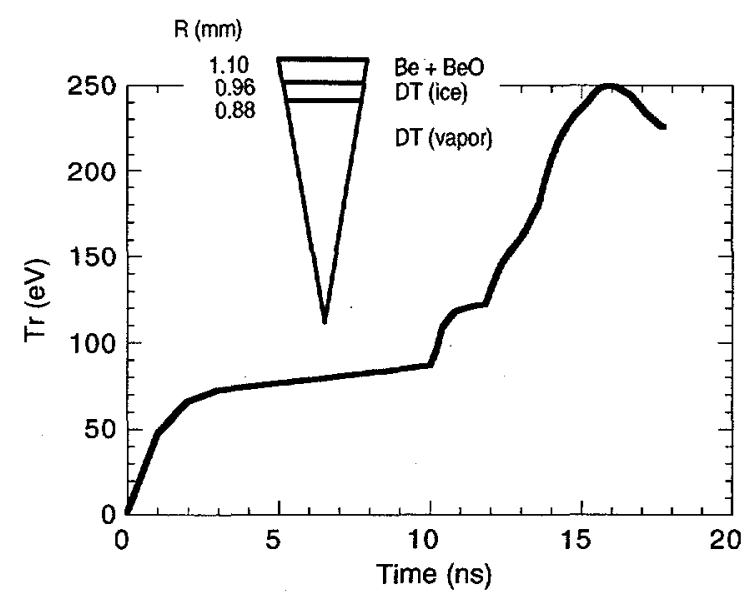

Figure 1: Dimensions and reduced NIF hohlraum drive for the $\beta$-layered ignition capsule with a $\mathrm{Be}+2 \% \mathrm{O}$ ablator. 


\section{DISCLAIMER}

This report was prepared as an account of work sponsored by an agency of the United States Government. Neither the United States Government nor any agency thereof, nor any of their employees, make any warranty, express or implied, or assumes any legal liability or responsibility for the accuracy, completeness, or usefulness of any information, apparatus, product, or process disclosed, or represents that its use would not infringe privately owned rights. Reference herein to any specific commercial product, process, or service by trade name, trademark, manufacturer, or otherwise does not necessarily constitute or imply its endorsement, recommendation, or favoring by the United States Government or any agency thereof. The views and opinions of authors expressed herein do not necessarily state or reflect those of the United States Government or any agency thereof. 


\section{DISCLAIMER}

Portions of this document may be illegible in electronic image products. Images are produced from the best available original document. 
uncertainties of $\sim 1-2 \%$.

As explained by Wilson et al. ${ }^{5}$, low opacity and high ablation velocity are two of the characteristics that help to make beryllium an excellent ablator material. One might ask whether or not liquid DT, with even lower opacity and higher ablation velocity, might be an even better ablator. In principle, the opacity of such an ablator could be controlled via a dopant in the low density polymer foam matrix that holds the liquid in place. The ablation front density could be increased from its very low initial value via controlled shock timing. The Fast Formed Liquid (FFL) surface technique proposed by Stephens ${ }^{10}$ might be used to create a polymer-free, pure DT layer on the inner surface of such a capsule, allowing the formation of a hot spot that is not contaminated with carbon or oxygen ions. In general, the ability to control ablator $x$-ray penetration and to select a DT vapor pressure are desirable from a capsule design standpoint. As described by Stephens ${ }^{10}$, an FFL capsule might also have some target fabrication and characterization advantages over the standard DT $\beta$-layer designs. The inherently low density, thick shell of a $\mathrm{DT}+\mathrm{CH}$ foam ablator does, however, present some significant disadvantages that will be explained in the discussion of Section III.

\section{NIF CAPSULE WITH A BE+2\%O ABLATOR}

The $\mathrm{Be}+\mathrm{BeO}$ ignition capsule is illustrated in Figure 1. The design is based upon the $10 \mathrm{MJ}$ yield $\mathrm{z}$-pinch ignition capsule (depicted in Fig. 5 of Ref. 9). For NIF, however, the outer "pulse shaping layer" of pure $\mathrm{BeO}$ is not required (due to the fact that NIF will have better pulse shaping capability than a z-pinch). When heated, the oxygen in the $\mathrm{Be}+\mathrm{BeO}$ ablator will be readily ionized to helium- and hydrogen- like configurations. Later, when the hohlraum temperature rises into the $200-250 \mathrm{eV}$ range, the oxygen in the blowoff plasma will become completely ionized (unlike a Cu dopant), allowing the full hohlraum X-ray flux to penetrate to the ablation surface. At the same time, as the unablated region heats up, the oxygen $\mathrm{K}$-edge moves upward in energy, absorbing the preheat photons in the dense region interior to the ablation front. Thus, in principle, an oxygen dopant in beryllium can prevent ablator burnthrough while at the same time allowing the maximum possible drive penetration and ablation pressure. As shown in Figure 1, the x-ray drive for this NIF capsule has a peak radiation field of $250 \mathrm{eV}$. Dittrich, et al. ${ }^{6}$, calculate that this drive would require $\sim 900 \mathrm{~kJ}$ of laser energy and $250 \mathrm{TW}$ of peak laser power. This represents approximately one half of the full NIF specifications ${ }^{1}$ of $1.8 \mathrm{MJ}$ and $500 \mathrm{TW}$. The implosion calculation of the $\mathrm{Be}+\mathrm{BeO}$ capsule has been optimized to produce a yield of 12 MJ. Calculated performance is, however, dependent

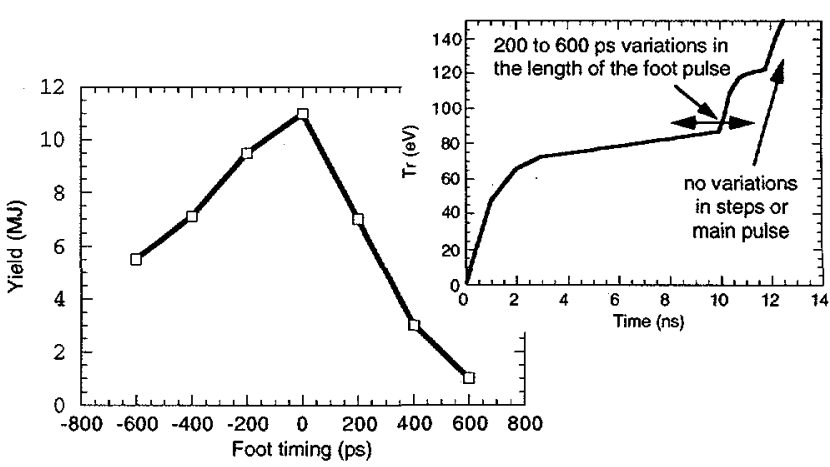

Figure 2: Uncertainties in the timing of the foot pulse can degrade the $\mathrm{Be}+\mathrm{BeO} \mathrm{NIF}$ ignition capsule performance.

upon knowledge (or calculation "inputs") of timing of the foot and steps, $x$-ray drive flux level, DT ice $\beta$-layer thickness, DT ice equation of state (EOS), ablator EOS, ablator opacity, and drive spectrum. An example of how uncertainties in the timing of the foot pulse radiation field can degrade the calculated capsule yield is quantified in Figure 2. Here, the total yield in each of a series of implosion calculations is plotted as a function of the variation ( \pm 200 to $600 \mathrm{ps}$ range) in the length of the foot of the $x$-ray input pulse. No variations were made in the rise to peak. Shortening the foot causes the first two shocks to converge within the ice layer. A lengthening of the pulse causes too much of the ice layer to decompress prior to second shock arrival. The implication of these intentionally mistimed calculations is that NIF hohlraum $\mathrm{x}$ ray diagnostics must have foot-level time resolution of better than $\sim 200 \mathrm{ps}$. It is also implied that the shot-to-shot repeatability in the timing of the laser + hohlraum foot pulse (as seen by the capsule) must be better than $200 \mathrm{ps}$.

Time resolution is critical, but, even with perfect timing, uncertainties in the power level of the radiation flux during the foot and first step can significantly degrade the calculated capsule yield. This is due to the change in shock timing that accompanies the increase in ablation pressure and, hence, in shock velocity with drive temperature (eg., see Fig. 3 of Ref. 11). Figure 3 quantifies this net effect. Here, the total yield in each of a series of calculations is plotted as a function of the variation $( \pm 25 \%$ in flux or $\pm 6 \%$ in temperature) made in the level of the foot + first step $\mathrm{x}$-ray input. No variations were made in the peak flux or timing of the pulse shape. The calculations imply that the NIF hohlraum $x$-ray diagnostics must be designed with foot-level radiation flux resolution of better than $\sim 10 \%$. Also implied is that the shot-to-shot radiation temperature level of the hohlraum foot pulse (as seen by the capsule) must be accurate to within $\sim 2 \mathrm{eV}$.

The yield variations shown in Figures 2 and 3 are caused by the resulting changes in shock timing. The importance of shock timing is largely due to the 


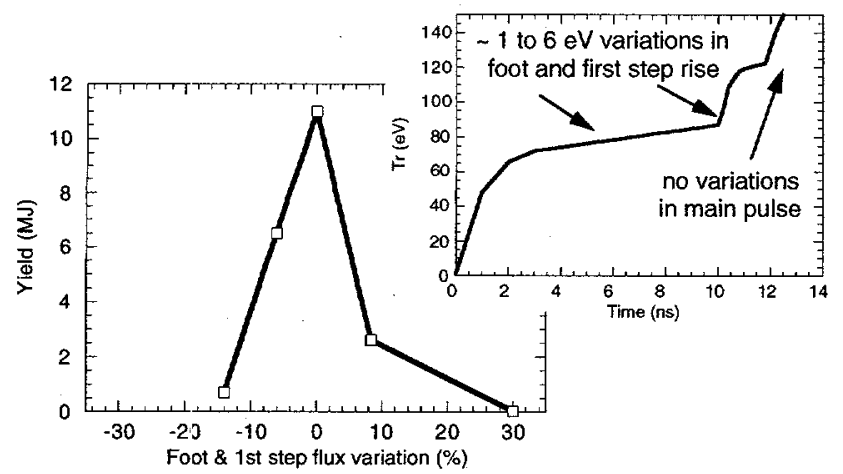

Figure 3: Uncertainties in the $x$-ray flux during the foot and step can degrade the $\mathrm{Be}+\mathrm{BeO}$ capsule peformance.

requirement that some of the hot spot mass in a $\beta$-layered ignition capsule must originate at the inner layer of the DT ice. Timing with shocks converging too far inside (or outside) the ice layer will be non-optimal. This observation implies that, even if the timing and flux levels of the laser and $x$-ray pulse shape were to be perfectly measured and reproduced, an inadequate characterization of the ice layer thickness could still result in non-optimal capsule performance. This variation is quantified in Figure 4 (left hand side) for a series of calculations that used identical $\mathrm{x}$-ray drive pulse shapes. The total yield in each calculation is plotted as a function of the initial ice layer thickness (which was varied by \pm 5 to 10 microns). The results indicate that preshot characterization of the DT ice $\beta$-layer must be accurate to within $\sim 5 \mu \mathrm{m}$.

Descriptions of ablator experiments and examples of how the interdependence of radiation temperature, ablation pressure, opacity, EOS, and shock velocity uncertainties effect computational predictive capabilities are provided in Reference 11. As described in that article, radiationhydrodynamics ICF implosion calculations utilize "subcalculations" and "physics packages" that could potentially be supplying incremental bits of inaccurate information. The right hand plot in Figure 4 provides an example of how calculated shock timing and yield can be altered by
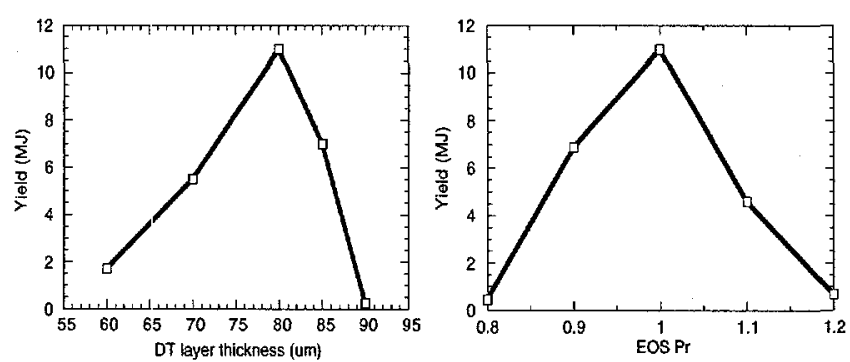

Figure 4: Uncertainties in DT ice layer thickness or ablator equation of state can significantly alter the calculation. potentially inaccurate knowledge of the ablator EOS. (This might very well be the case for the $\mathrm{Be}+\mathrm{BeO}$ mixture being considered here). This plot shows results from a series of calculations that used identical $\mathrm{x}$-ray drive pulse shapes. The only variation involves a hypothetical multiplier $( \pm 10$ to $20 \%$ ) applied to the ablator pressure during the foot pulse. The results imply that uncertainties in the EOS subcalculations and/or tables can significantly alter the calculated capsule yield.

The sensitivity results shown in Figures 2-4 are based upon calculations in which it is assumed that only one variable is uncertain and that all other variables are known exactly. As one might imagine, however, combined uncertainties can have greater impact than isolated, individual issues. For example, a combination of uncertainties of $200 \mathrm{ps}$ in the foot $+2 \mathrm{eV}$ in the foot +5 $\mu \mathrm{m}$ in the DT ice thickness results in a calculation that produces only $\sim 1 \%$ of the original design yield. Thus, the tolerances of $200 \mathrm{ps}, 2 \mathrm{eV}$, and $5 \mu \mathrm{m}$ indicated in Figures 2-4 are viewed as approximate upper limits for the NIF ignition campaign shock timing diagnostics. For example, a VISAR + high-resolution radiography diagnostic has been demonstrated by Collins, et al. ${ }^{12}$ and is currently being refined for planar shock timing resolutions of $\sim 100$ ps.

The degree of BeO uniformity in this capsule design might pose interesting issues from both the target fabrication and implosion calculation standpoints. Oxygen, unlike $\mathrm{Cu}$, is not soluble in beryllium. For a power metallurgy fabrication process, the oxygen content would be controlled by adjusting either the exposure to oxygen (for given size $\mathrm{Be}$ particle) or the size of the $\mathrm{Be}$ particles used (for a given exposure). For $2 \%$ atomic oxygen, the mass ratio of the $\mathrm{BeO}$ layer to the pure $\mathrm{Be}$ in each particle would have to be $\sim 5 \%$ (which is comparable to what is found in some grades of commercially available Be). Given this fabrication scenario, oxygen uniformity would be related to the size of the Be particles. An alternative possibility of creating a $\mathrm{Be}+\mathrm{BeO}$ ablator via $\mathrm{Be}$ sputter deposition in the presence of a controlled oxygen background might represent a technique for providing a more uniform oxygen concentration and provide a possibility for radial concentration gradients. In either case, an interesting radiation-hydrodynamics computation for future work would be to determine the maximum particle size or oxygen non-uniformity that would be acceptable from the standpoint of seeding Rayleigh-Taylor instabilities in the imploding shell. Other potential areas of concern include: 1) control and measurement of the cryogenic hohlraum and capsule temperature profile $(\sim \mathrm{mK} / \mathrm{mm}) ; 2)$ ice participation in hot spot formation; 3) preshot measurement of the ice layer thickness and faceting; and 4) filling of the $\mathrm{Be}+\mathrm{BeO}$ shell. In principle, a wetted foam design could alleviate these concerns. 


\section{NIF CAPSULE WITH A DT+CH ABLATOR}

A DT $-\mathrm{CH}$ ablator capsule with a FFL inner surface is shown in Figure 5. A $1 \mathrm{D}$ implosion calculation using a 20 $\mu \mathrm{m} \mathrm{CF} \mathrm{CF}_{2}$ outer coating ignites and produces a $5 \mathrm{MJ}$ yield. The hot spot energy density is higher than the $\mathrm{Be}+\mathrm{BeO}$ design for the same peak drive $(250 \mathrm{eV})$ parameters. The pure DT inner surface would be formed via the FFL concept proposed by Stephens ${ }^{10}-$ 1) liquid DT is wicked into a foam shell and frozen; 2) the ice is melted just before the shot; 3 ) the liquid expands by $\sim 10 \%$, extrudes from the foam, forming a smooth surface; and 4) the shot occurs before the liquid surface can de-center. Since the DT is liquid, the designer can select from a wide range of the DT vapor pressures and vary the fraction of hot spot material that must originate at the inner surface of the ice layer. The wetted, doped foam ablator provides an ability to control $x$-ray penetration and ablation rate. The full density outer layer forces the liquid DT to extrude inward, but also provides a mechanism for increasing the $\mathrm{DT}+\mathrm{CH}$ density to the $\sim 1 \mathrm{~g} / \mathrm{cm}^{3}$ level prior to its use as an ablator.

The consequences of the longer drive foot might be significant. It is not clear that the NIF laser could produce the $\sim 24$ ns pulse required for this FFL capsule. The capsule is $-20 \%$ larger than the $\mathrm{Be}+\mathrm{BeO}$ capsule and might require a larger hohlraum to deliver adequate symmetry. Also, the longer foot will result in more wall motion, which might disrupt symmetry or reduce conversion efficiency. The finite foam cell size would result in a seed for instabilities that is very analogous to the beryllium particle size issue discussed in the previous section in which thin layers of high opacity surround $\sim 1$ to $10 \mu \mathrm{m}$ pockets of low opacity. Finally, the thin, full density outer layer (eg., doped $\mathrm{CH}, \mathrm{PVA}, \mathrm{CF}_{2}$ ) must be carefully designed so as to avoid excessive instability growth during the foot pulse.

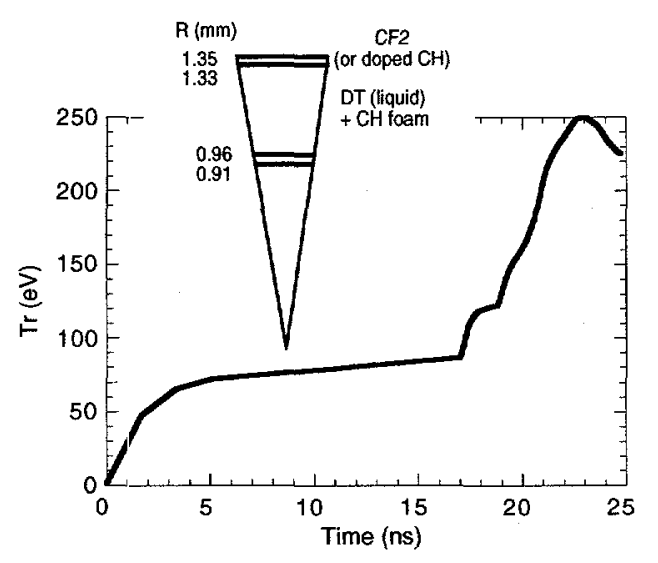

Figure 5: The FFL capsule with a DT+CH ablator.

\section{ACKNOWLEDGMENTS}

The NIF ignition planning team is thanked for many useful interactions. In particular: T. Dittrich (LLNL) provided the NIF "reduced drive" pulse shape; R. Margevicius (LANL) and $R$. Wallace (LLNL) provided descriptions of beryllium fabrication processes; R. Stephens (GA) provided information on his FFL concept; and R. Leeper (SNL) provided managerial support.

*Sandia is a multi-program laboratory operated by the Sandia Corporation, a Lockheed Martin Company, for the U. S. Department of Energy under Contract No. DE-AC04-94AL85000

\section{REFERENCES}

1. J. D. Kilkenny, T. P. Bernat, B. A. Hammel, R. L. Kauffman, O. L. Landen, J. D. Lind,, B. J. MacGowan, J. A. Paisner, H. T. Powell, "Lawrence Livermore National Laboratories Activities to Achieve Ignition by $X$-ray Drive on the National Ignition Facility," Laser and Particle Beams, 17, 159 (1999).

2. T. P. Bernat, "The National Ignition Campaign", these proceedings.

3. R. J. Leeper, et al, "Target Diagnostic System for the National Ignition Facility," Rev. Sci. Instrum., 68, 868 (1997).

4. T. R. Dittrich, et al., "Review of Indirect-Drive Ignition Design Options for the National Ignition Facility," Phys. Plasmas, 6, 2164 (1999).

5. D. C. Wilson, et al., "The Development and Advantages of Beryllium Capsules for the National Ignition Facility," Phys. Plasmas, 5, 1953 (1998).

6. T. R. Dittrich, S. W. Haan, M. M. Marinak, S. Pollaine, R. McEachern, "Reduced Scale National Ignition Facility Capsule Design," Phys. Plasmas, $\underline{5}$, $\underline{3708}$ (1998).

7. D. C. Wilson, P. A. Bradley, S. R. Goldman, N. M. Hoffman, R. E. Margevicius, R. B. Stephens, R. E. Olson, "Developments in NIF Beryllium Capsule Design," these proceedings.

8. G. O. Allshouse, R E. Olson, D. A. Callahan-Miller, M. Tabak, "Deposition and Drive Symmetry for Light Ion ICF Targets," Nuclear Fusion, 39, 893 (1999).

9. R. E. Olson, et al., "Indirect-Drive ICF Target Concepts for the X-1 Z-Pinch Facility," Fusion Technology, 35, 260 (1999).

10. R. B. Stephens, "Fast-Formed Liquid Surfaces for Inertial Confinement Fusion Target Shells," Proc. IEEE/NPSS, p. 753 (1993).

11. R. E. Olson, et al., "Inertial Confinement Fusion Ablator Physics Experiments on Saturn and Nova," Phys. Plasmas, 4, 1818 (1997).

12. G. W. Collins, et al., "Measurements of the Equation of State of Deuterium at the Fluid Insulator-Metal Transition," Science, 281, 1178 (1998). 